\title{
Guest Editor Preface
}

It is with a great pleasure that I preface this special issue of the Journal of Sustainable Architecture and Civil Engineering, which comprises invited papers submitted to the 1st Forum Wood Building Baltic 2019, organized between 27 February - 1 March 2019 in Tallinn, Estonia.

The Forum Wood Building Baltic 2019 conference was a fantastic opportunity for scientists and practitioners to meet and exchange experiences and to learn from the best within the field. The conference was organized by Tallinn University of Technology in collaboration with Estonian Association of Civil Engineers, Estonian Woodhouse Association, Estonian Forest and Wood Industries Association, and Forum Holzbau.

Forum Wood Building Baltic is the main conference for technical topics of wooden buildings: building physics, fire safety, and wooden nearly zero energy buildings etc. in the countries around Baltic Sea. Participants were from following countries: Austria, Canada, Switzerland, Germany, Denmark, Estonia, Finland, Greece, Lithuania, Latvia, Norway, Sweden, United Kingdom.

Scope of the conference was

_ Building Physics (heat, air and moisture; moisture safety)

Nearly Zero Energy Buildings (real energy use, cost reduction)

_ Fire Safety (separating and load-bearing functions, protection)

- Cross Laminated Timber buildings (materials, structures)

This special issue includes nine articles, which cover different aspects from energy performance to building physics.

The European energy policy pushes the member states to transform building stock into nearly Zero-Energy Buildings (nZEB). Kuusk et al collected data collected from existing nZEB day-care centres to analyse possible differences between predicted and actual energy performance and indoor climate. A more accurate and robust commissioning, design and construction process is needed for future nZEB day-care centers. The overall indoor environment was very good as occupant satisfaction was $90 \%$ or more. In majority of day-care centers, measured energy consumption is higher or even significantly higher than designed values.

Dodoo studied the lifecycle primary energy and greenhouse gas implications of five multi-storey building versions with different construction systems, considering flows from the production, operation and end-of-life phases and the full natural resources chains. Results showed that the operation phase dominates the lifecycle primary energy use of the building system versions. The primary energy for building production is $4-18 \%$ lower for the analysed timber-based building systems compared to the reinforced concrete building alternative. The massive timber building system gives the lowest lifecycle primary energy and greenhouse gas balances.

Due to the increased interest for wood buildings by the market, new technologies based on cross laminated timber (CLT) have been developed, enabling an evolution of high-rise buildings. The main problem with wood and timber as a construction material is that it is sensitive to moisture and water causing mould and/or rot damages, as well as insect pests, which might cause indoor air problems but also structural failures shortening the life time of the building. Mjörnell and Olsson recommend that timber is not exposed to water or long periods of high relative humidity (weeks), which means that design of moisture safe, robust structures, weather protection and moisture safe handling of material at the building site and construction methods must be used.

A well-insulated, airtight and thermal bridge free building envelope is a key factor for nZEB. Hallik and Kalamees give the overview about airtightness of Estonian wooden buildings. The airtight- 
ness of Estonian wooden buildings has improved by a factor of 10 since the minimum requirements for energy efficiency have taken effect. Systematic measurement practice also contributed to significantly lower air leakages.

Geving et al. studied effect of repeated moisture cycles on the air tightness of traditional clamped vapour barrier joints. The results showed that the first drying cycle resulted in significant increase of air leakage for clamped joints in the wind- and vapour barrier layer. Adhesive tape on the joints resulted in the greatest reduction in leakage numbers where the center distance between the nails was high.

Current method of façade retrofitting with additional heat insulation is time consuming and does not always prove the desired efficiency levels. The use of prefabricated timber-based panels provides more finishing options, thicker insulation layers, optimal window placement, and faster construction rate. Bumanis and Pugovics presented experience from low energy consumption façade pilot project. After three years of service it is visible, that conditions within the panel and between the panel and existing wall are optimal and no formation of dew point was observed.

Kalbe and Kalamees studied the influence of window frame thermal transmittance, window frame height and window installation depth on the energy demand of an nZEB and showed that show that decreasing the thermal transmittance and height of the window frame have a significant effect on the energy demand of the nZEB, while the effect of optimising window installation depth is insignificant.

The most commercial insulation products today are based on oil. Switching to more environmentally friendly materials to insulate the dwelling's shell has to be everybody's primary target. Ninikas et al. studied thermal properties of insulation boards made of tree bark and hemp residues.

Due to regulations for building acoustics and developments in the construction industry, there is a demand for higher standards to be met in dwellings, especially for residential timber multi story buildings. Bard-Hagberg and Vardaxis evaluated acoustic comfort in typical residential family buildings in Sweden. The results indicate that impact noise can be an issue in timber buildings. The most important noise types that generate annoyance are: machinery noise in the building, neighbor's walking and activity from the floor above or below, low frequency noise from outside. Slight annoyance was also reported due to transmission of neighbors' low frequency music and conversations.

Prof. dr. Targo Kalamees

Guest Editor

Tallinn University of Technology 